\title{
Power Quality Disturbance Location Method based on Cross-Feedback - Recursive Least Squares
}

\author{
Shao Zhenhua ${ }^{\mathrm{a},{ }^{*}, \text { Chen Tianxiang }}{ }^{\mathrm{a}}$, Chen Li-an ${ }^{\mathrm{a}}$, Sun Zelong ${ }^{\mathrm{a}}$, Yan Qichen ${ }^{\mathrm{a}}$, Guo Yanyan ${ }^{\mathrm{a}}$, Tao \\ Xianliang ${ }^{\mathrm{a}}$ and Zheng Meirong ${ }^{\mathrm{b}}$
}

\author{
${ }^{a}$ Fujian Province Key Laboratory of High Voltage Engineering Xiamen University of Technology Xiamen China \\ ${ }^{b}$ Fujian Province Electric Power Maintenance Company, Xiamen, China
}

\begin{abstract}
Due to the randomness and complexity of power quality disturbances, there is lack of mature and reliable detection and analysing methods on power quality disturbance, especially in the construction site with the changeable operation condition. In order to deal with the problems of non-stationary power quality signals and spectrum leakage, a new $\mathrm{CF}$ Recursive Least Squares (CF-RLS) based on blind sources separation method is proposed in this paper. Furthermore the way of converging on the proposed method is based on the maximum negative entropy gradient value. In this way, the verges can be detected and the CF-RLS method can meet the requirement of signal reconstruction condition. With the help of Matlab 7.0, the simulation cases with the power system harmonics with single disturbance and mixed disturbance are discussed. Moreover the simulation results show that the harmonics parameters, including amplitudes, phase angles and disturbance time, can be detected precisely. At last, the proposed method can completely meet the requirements of the power quality disturbance location.
\end{abstract}

Keywords: Blind Sources Separation (BSS), Cross-Feedback Recursive Least Squares (CF-RLS), Error Correction Term (ECT), harmonics location analysis, power quality.

\section{INTRODUCTION}

With widely use of nonlinear load, especially the power electronic devices and some impact loads, more and more researchers pay attention on the increasing serious power quality of power grid [1-4]. Furthermore power quality pollution does harm the safe and economics operation of power grid. Even worse, increasing line loss, misoperation of relay protection, enlarged measuring errors on electronic instruments, frequently burning on inter-fuse of $10 \mathrm{Kv}$ capacitor and insulation aging for large generator are proved to be connected with the deterioration of power quality [5-9]. So it is very meaningful of long-term supervision and intelligent management on power quality signals. On one hand, accurate analysis on stationary power quality signals does well to the development of power quality management and power system dispatching. On the other hand, position and recognition on power quality transient disturbance also provides evidence for electric energy measurement and active power filter. Nowadays the study on power quality disturbance location has become a hot issue [10-17].

Fast Fourier Transform (FFT), SFFT, Wavelet Transform and Hilbert-Huang Transform are the mainstream timefrequency analysis methods. However, accurate position and recognition on power quality transient disturbance is very

*Address correspondence to this author at the Electrical Engineering and Automation Xiamen University of Technology, LI Gong Road 600, Xiamen, China; Tel 0592-6291057; E-mail: 2011110608@xmut.edu.cn difficult for us. Firstly, FFT is inevitable to cause the spectrum leakage and fence effect because of truncation and discreteness in signal collection. Secondly, these detection methods are sensitive to background noises, Filtering processing for eliminating low-frequency disturbance and noise signal carried out is very necessary. Thirdly, power quality transient disturbance has the characteristics of large quantity, many types and has a complex nature. Many researchers pay much more attentions on ANN and window interpolation for help [18-20].

With consideration of advantages of Blind Sources Separation (BSS), an improved Recursive Least Squares (CFRLS) is proposed in this paper. At last the CF-RLS can meet the requirement of signal reconstruction condition. Moreover the proposed method has a good anti-noise performance. The simulation results show that the proposed method can accurately analyse parameters of power quality transient disturbance, and it can detect and locate the time and amplitude of transient disturbance. IN one word, the proposed method has a high application value on power quality disturbance location.

\section{THEORETICAL BASIS}

\subsection{Blind Sources Separation}

All authors must strictly follow the guidelines below for preparing illustrations for publication. If the figures are found to be sub-standard, then the manuscripts will be 


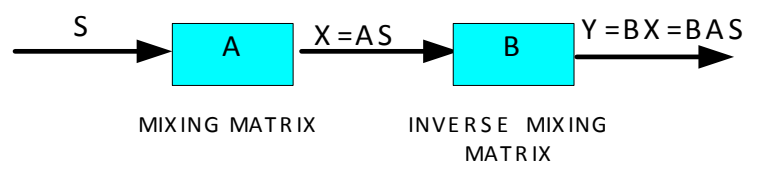

Fig. (1). Derivation process of ICA.

rejected/ and the authors offered the option of figure improvement professionally by Eureka Science. The costs for such improvement will be charged to the authors.

If there are $\mathrm{N}$ unknown signals $S_{i}(t), i=1,2, \ldots, N$, there exist column vectors $S(t)=\left[S_{1}(t), \ldots, S_{N}(t)\right]^{Y}$, where $\mathrm{t}$ is the discrete time, and $\mathrm{t}=0,1,2 \ldots$ If Mixing Matrix $\mathrm{A}$ is a $M \times N$ matrix ,then column vectors $X(t)=\left[X_{1}(t), \ldots, X_{M}(t)\right]^{T}$ and $X(t)$ is made up by $X i(t)$, where $i=1, \ldots, M$. Then the column vectors satisfy

$X(t)=A S(t)$, where $M>N$

Where $\mathrm{X}(\mathrm{t})$ is known and $\mathrm{A}$ is unknown , the solving nonlinear equations (1) is called BSS.

\subsection{Independent Component Analysis}

There are several assumptions that should be considered:

a) Independent component signals are statistically independent but linearly mixed;

b) Independent component signals are followed nonGaussian distribution;

c) The Mixing Matrix $A$ is an $\mathrm{N}^{*} \mathrm{~N}$ matrix. Then the BSS can be changed to ICA.

d) If there is a $\mathrm{N}^{*} \mathrm{~N}$ Inverse Mixing Matrix $W=\left(w_{i j}\right)$,

e) X can be obtained by $\mathrm{W}$-transform, that is

$Y(t)=W X(t)=W A S(t)$

Where $\mathrm{WA}=\mathrm{I}\left(\mathrm{N}^{*} \mathrm{~N}\right.$ unit matrix $), \mathrm{Y}(\mathrm{t})=\mathrm{S}(\mathrm{t})$; The derivation process can be shown in Fig. (1).

\subsection{CF-RLS}

The projection pursuit direction of Fast ICA is based on the maximum negative entropy gradient value.

\subsubsection{Definition of Negative Entropy Value}

$N_{g}(Y)=H\left(Y_{\text {Gauss }}-H(Y)\right.$

Where $Y_{\text {Gauss }}$ is the Gauss random variable with the same variance of $\mathrm{Y}$, and $\mathrm{H}()$ is the differential entropy of random variable.

Then

$H(Y)=-\int \rho_{\mathrm{Y}}(\xi) \lg \rho_{Y}(\xi) d \xi$
Where $\rho_{Y}(\xi)$ is the probability density function of Y, unfortunately $\rho_{Y}(\xi)$ is not east to get.

Then

$N_{g}(Y)=\left\{E[g(Y)]-E\left[g\left(Y_{\text {Gauss }}\right)\right]\right\}^{2}$

Where $\mathrm{E}[]$ is the mean operation and $\mathrm{g}()$ is the nonlinear function, such as $g_{1}(y)=\tanh (y)$,

$$
g_{2}(y)=y \exp \left(-y^{2} / 2\right) \text { or } g_{3}(y)=y^{3} \text { etc. }
$$

\subsubsection{RLS}

The flow chart of RLS is shown as following:

At first, the maximum negative entropy approximate value can be obtained by optimizing searching of $E\{G(W T X)\}$..

Secondly, according to the pre-conditions of KuhnTucker, the optimized value can be obtained by the following equations:

$\left\{\begin{array}{c}E\left\{X_{g}\left(W^{T} X\right)\right\}+\beta W=0 \\ E\left\{\left(W^{T} X\right)^{2}\right\}=\|W\|^{2}=1\end{array}\right.$

where $\beta$ is fixed value, and $\beta=E\left\{W_{0}^{T} X_{g}\left(W_{0}^{T} X\right)\right\}$, where $\mathrm{W}_{0}$ is the optimizing value of $\mathrm{W}$.

Thirdly, the jacobian matrix of $F$ is

$J F(W)=E\left\{X X^{T} g^{\prime}\left(W^{T} X\right)\right\}-\beta I$

In order to get a quick-reading flow sheet, the approximate Newton iterative formula is shown in the following equation:

$$
\begin{aligned}
& W^{*}=W-\left\{E\left[X g\left(W^{T} X\right)\right]-\beta W\right\} / \\
& \left\{E[] g^{\prime}\left(W^{T} X\right)-\beta\right\} \\
& W=W^{*} /\|W\|
\end{aligned}
$$

\subsection{3. $C F-R L S$}

With the help of RLS method, voltage swell, voltage dip and voltage interruption with harmonics can be identified. While there are some errors and deviations on amplitude measurement [21], especially in FFT, SFFT and S transform etc. In order to deal with the shortcoming, the CrossFeedback network is introduced in this paper (which is shown in Fig. 2). 


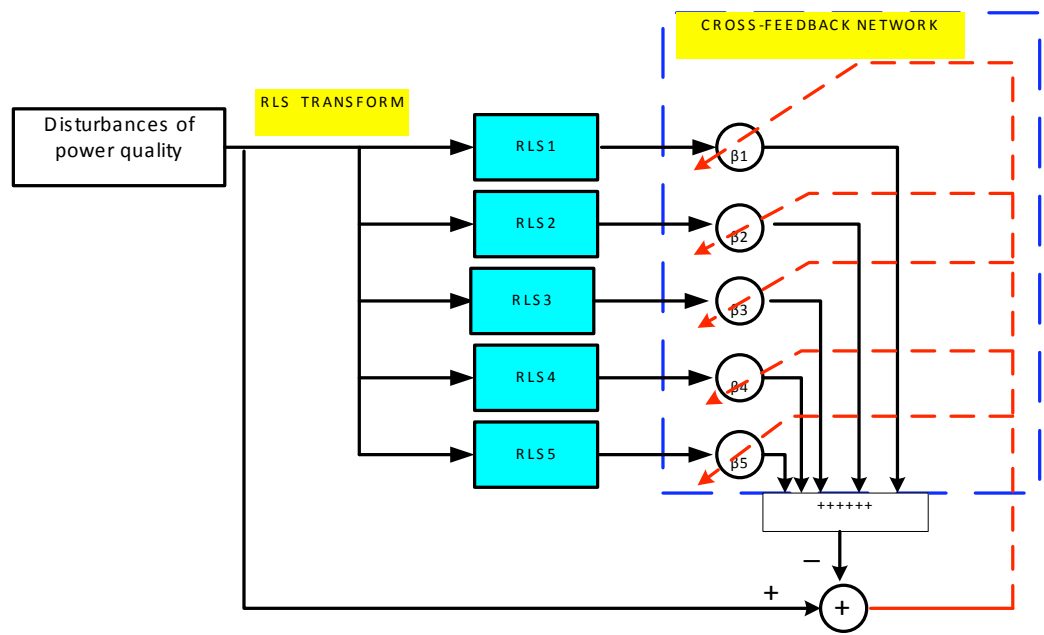

Fig. (2). Cross-Feedback Network.

Table 1. Complex disturbance signals.

\begin{tabular}{|c|c|}
\hline Number & Expression \\
\hline \hline & $\mathrm{S} 2=\cos (120 \pi)+\cos (720 \pi)+$ \\
$\mathrm{cos}(720 \pi+6 \sin (120 \pi))+$ \\
squarewave $(180 \mathrm{~Hz})+$ \\
& rand white noise \\
\hline & $S 1=\cos (100 \pi+1.5)-\cos (100 \pi+2)$ \\
II & $+\cos (100 \pi)+$ squarewave $(120 H z)$ \\
& + rand white noise \\
\hline
\end{tabular}

As can be seen from the Fig. (2), the cross-feedback network can accelerate the rate of convergence, and can realize the multivariable decoupling control. In this way, the problems of non-stationary power quality signals and spectrum leakage may be solved smoothly. Moreover $\beta_{i} i=1, \ldots, n$ are the adaptive parameters, the initial values of $\beta_{i} i=1, \ldots, n$ are 1.0. The adjustment of $\beta$ is connected with the comparison between initial signals and composited signals.

\section{SIMULATION EXPERIMENTS VERIFICATION}

\subsection{Complex Disturbance Signal Decomposition}

With the help of MATLAB 7.0,the complex disturbance signals are produced as following (Table 1), 1000 sampling points in one power cycle, and the sampling time $\mathrm{t}=5 \mathrm{~T}$, then there are 5000 sampling points in the data set. Moreover, Gauss-white noise and square wave (amplitude unit voltage) are induced in the simulation with $\mathrm{SNR}=25 \mathrm{~dB}$.

In order to have a good contrast result, the NLS method and BP-NLS method are simulated in this paper. The error correction term(ETC) of power quality disturbances $\mathrm{I}$ is shown in Fig. (3). And location of power quality disturbances $I$ is shown in Fig. (4). Furthermore, the ETC of power quality disturbances II is shown in Fig. (5). And location. of power quality disturbances II is shown in Fig. (6).

As can be seen from Fig. (3) and Fig. (5), CF-NLS method has a better convergence rate than NLS method. On the other hand, as can be seen from Fig. (4) and Fig. (6), the different power quality disturbances can be identified and the start-halt instant can be located accurately. Although the white noise has a slight influence on the amplitude location, the different types of power quality disturbances can be located directly. Furthermore, as can be seen from Fig. (7), the signal error is too small $(0.2 \%)$ to the location of disturbances.

\subsection{Simulations on Typical Signals}

In order to test the efficiency of CF-RLS, five types power quality disturbances are shown in Table 2 . They are voltage swell, voltage dip, voltage interruption, electro- magnetic pulse, harmonics and transient oscillation.

\subsection{Location of Disturbances of Simulations Example}

The feasibility of CF-NLS method is proved by Matlab/Simulink. The whole simulation time is $0.4 \mathrm{~s}$. Firstly, there is no reactive power component in initial signals. Moreover different frequency band signals keep stable. Secondly, the change point of frequency is $0.2 \mathrm{~s}$ (that is $200 \mathrm{~ms}$ ), 


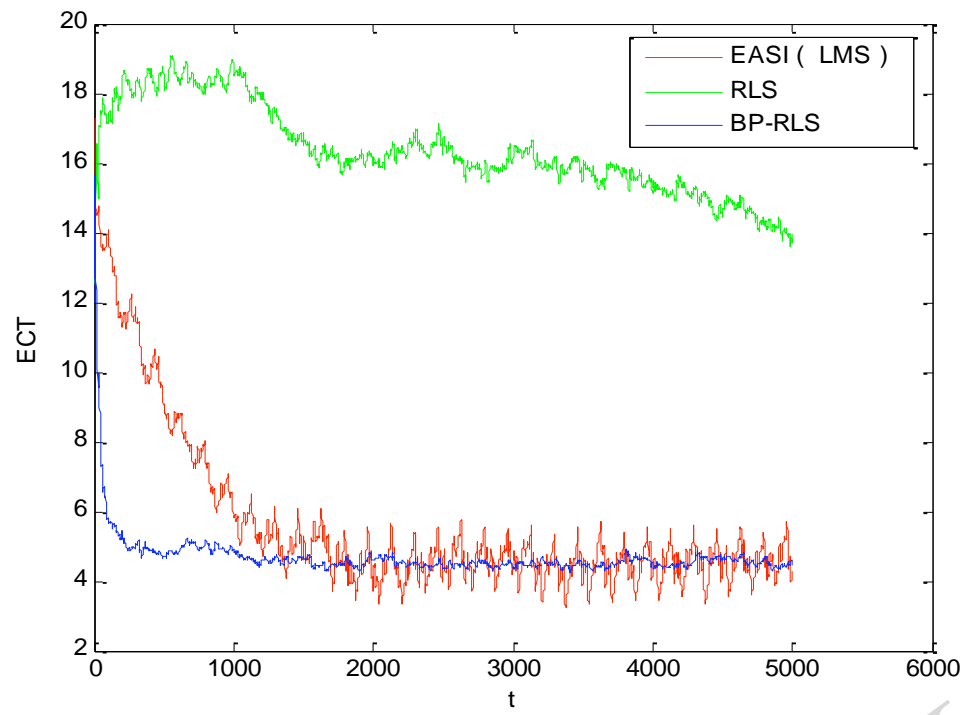

Fig. (3). ECT between LMS and CF-RLS power quality disturbances I.
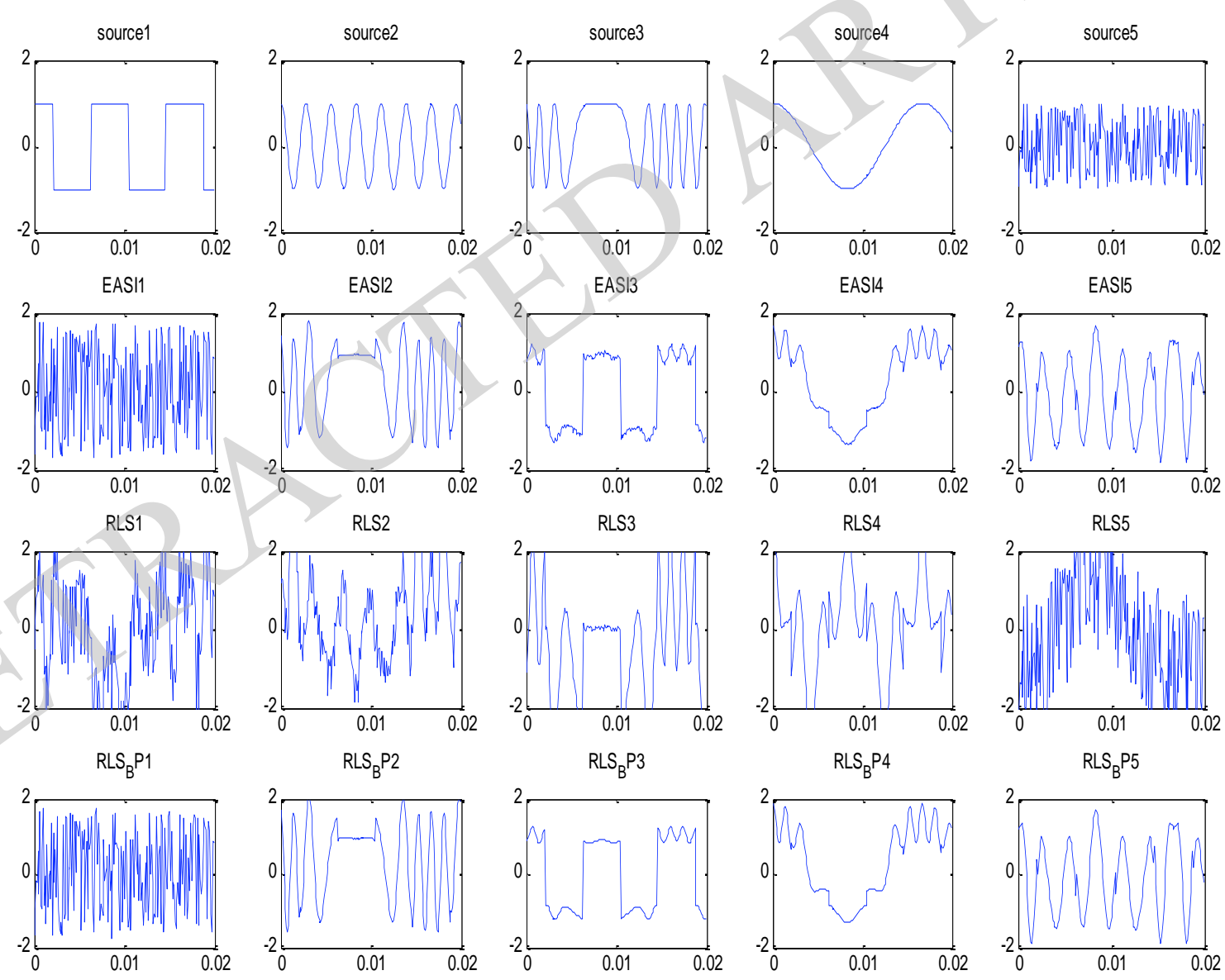

Fig. (4). Location of power quality disturbances I. 


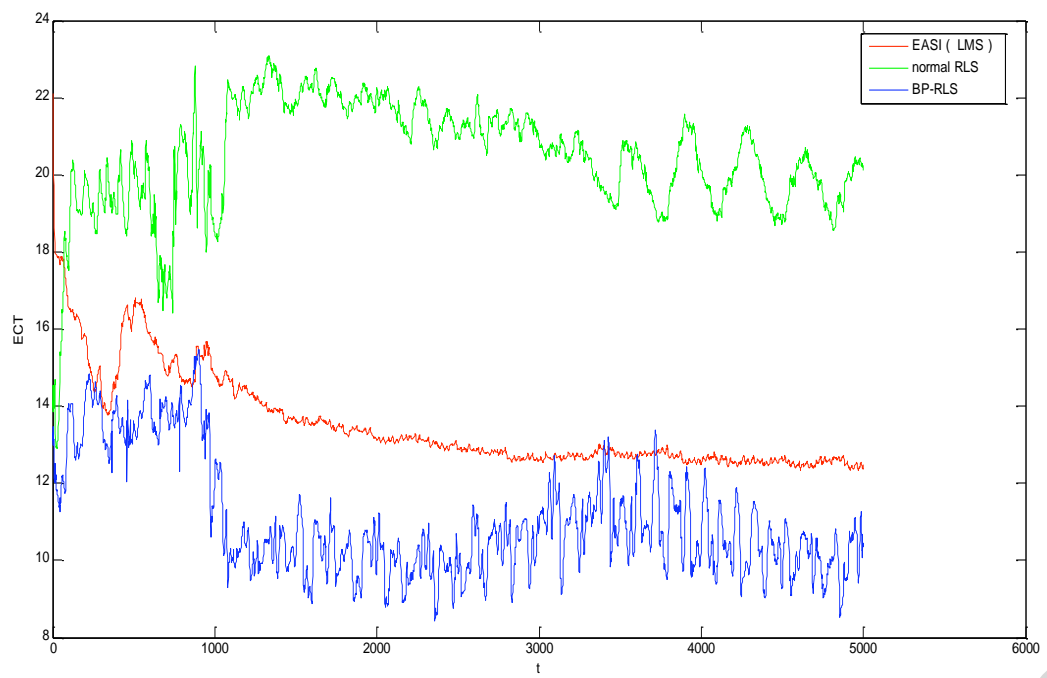

Fig. (5). ECT between LMS and CF-RLS of power quality disturbances II.
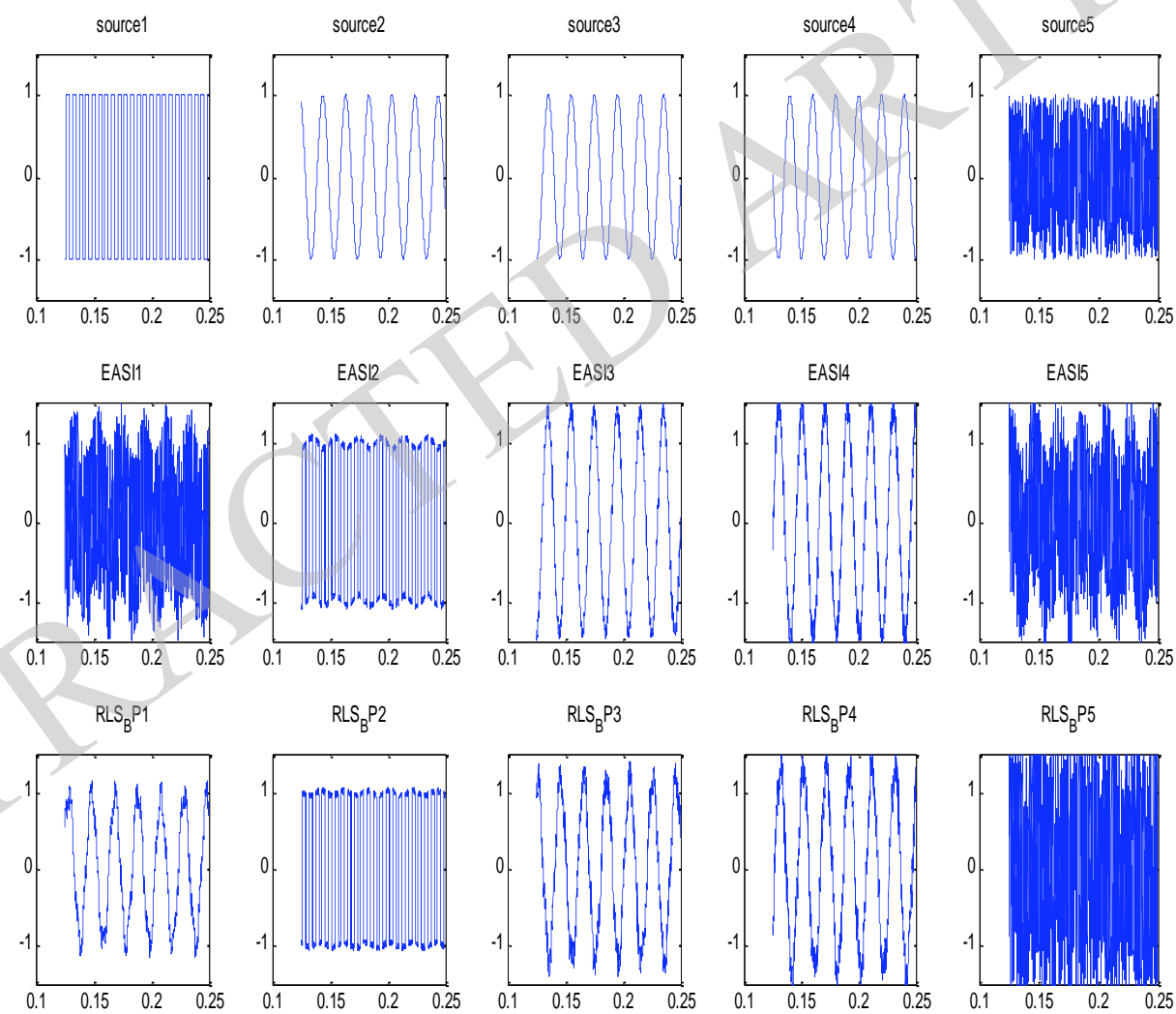

Fig. (6). Location of power quality disturbances II.

Table 2. Power quality disturbances.

\begin{tabular}{|c|c|c|}
\hline Disturbances & Parameters & Expression \\
\hline \hline Voltage & $0.1 \leq \alpha \leq 0.8$ & $T(t)=A\left\{1+\alpha\left[u\left(t_{2}\right)\right.\right.$ \\
swell & $T \leq t_{2}-t_{1} \leq 6 T$ & $\left.\left.-u\left(t_{1}\right)\right]\right\} \sin (\omega t)$ \\
\hline
\end{tabular}




\begin{tabular}{|c|c|c|}
\hline Disturbances & Parameters & Expression \\
\hline $\begin{array}{l}\text { Voltage } \\
\text { dip }\end{array}$ & $\begin{array}{l}0.1 \leq \alpha \leq 0.9 \\
T \leq t_{2}-t_{1} \leq 6 T\end{array}$ & $\begin{array}{l}T(\mathrm{t})=A\left\{1-\alpha\left[u\left(t_{2}\right)\right.\right. \\
\left.\left.-u\left(t_{1}\right)\right]\right\} \sin (\omega t)\end{array}$ \\
\hline voltage interruption & $\begin{array}{c}\alpha>0.9 \\
T \leq t_{2}-t_{1} \leq 9 T\end{array}$ & $\begin{array}{l}\mathrm{T}(\mathrm{t})=A\left\{1-\alpha\left[u\left(t_{2}\right)-\right.\right. \\
\left.\left.u\left(t_{1}\right)\right]\right\} \sin (\omega t)\end{array}$ \\
\hline harmonics & $\begin{aligned} 0.1 \leq \alpha_{3}, \alpha_{5}, \alpha_{7} \leq 0.9 & \alpha_{1}^{2}+\alpha_{3}^{2}+\alpha_{5}^{2} \\
& +\alpha_{7}^{2}=1\end{aligned}$ & $\begin{array}{l}T(t)=A\left[\alpha_{1} \sin (\omega t)\right. \\
+\alpha_{3} \sin (3 \omega t)+ \\
\alpha_{5} \sin (5 \omega t)+ \\
\left.\alpha_{7} \sin (7 \omega t)\right]\end{array}$ \\
\hline transient oscillation & $\begin{array}{c}0.1 \leq \alpha \leq 0.8 \\
0 \leq t_{2}-t_{1} \leq 2 T 0.1 \leq \lambda \leq 0.2\end{array}$ & $\begin{array}{l}T(t)=A\{\sin (\omega t)+ \\
{\left[\alpha \exp \left(t-t_{1}\right) / \lambda\right] *} \\
\sin \left[\omega\left(t-t_{1}\right)\left[u\left(t_{2}\right)\right]\right. \\
\left.\left.-u\left(t_{1}\right)\right]\right\}\end{array}$ \\
\hline
\end{tabular}
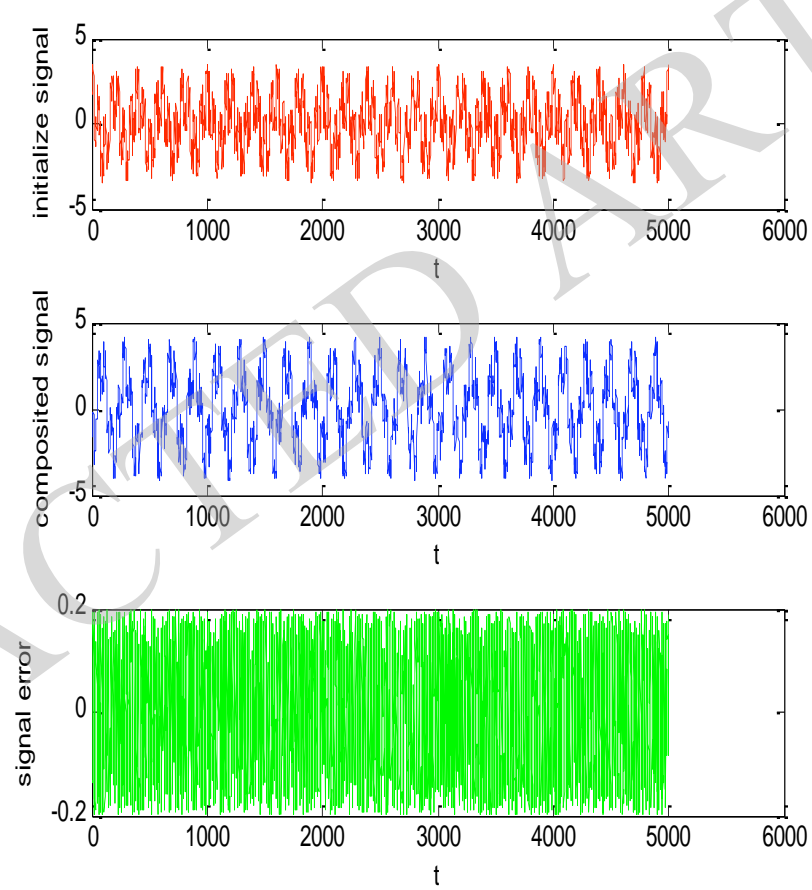

Fig. (7). Initialize signal, composted signal and signal error.

Table 3. Parameters of the input current.

\begin{tabular}{|c|c|c|c|}
\hline Component & Amplitude [p.u.] & T=0-0.2s & T=0.2-0.4s \\
\hline \hline fundamental & $1 \angle 0^{\circ}$ & $50 \mathrm{~Hz}$ & $49 \mathrm{~Hz}$ \\
\hline $5^{\text {th }}$ harmonic & $0.25 \angle 45^{\circ}$ & $5 * 50 \mathrm{~Hz}$ & $5 * 49 \mathrm{~Hz}$ \\
\hline $7^{\text {th }}$ harmonic & $0.25 \angle 180^{\circ}$ & $7 * 50 \mathrm{~Hz}$ & $7 * 49 \mathrm{~Hz}$ \\
\hline $11^{\text {th }}$ harmonic & $0.15 \angle 180^{\circ}$ & $11^{*} 50 \mathrm{~Hz}$ & $11^{*} 49 \mathrm{~Hz}$ \\
\hline White noise & $\mathrm{SNR}=20 \mathrm{~dB}$ & & \\
\hline
\end{tabular}



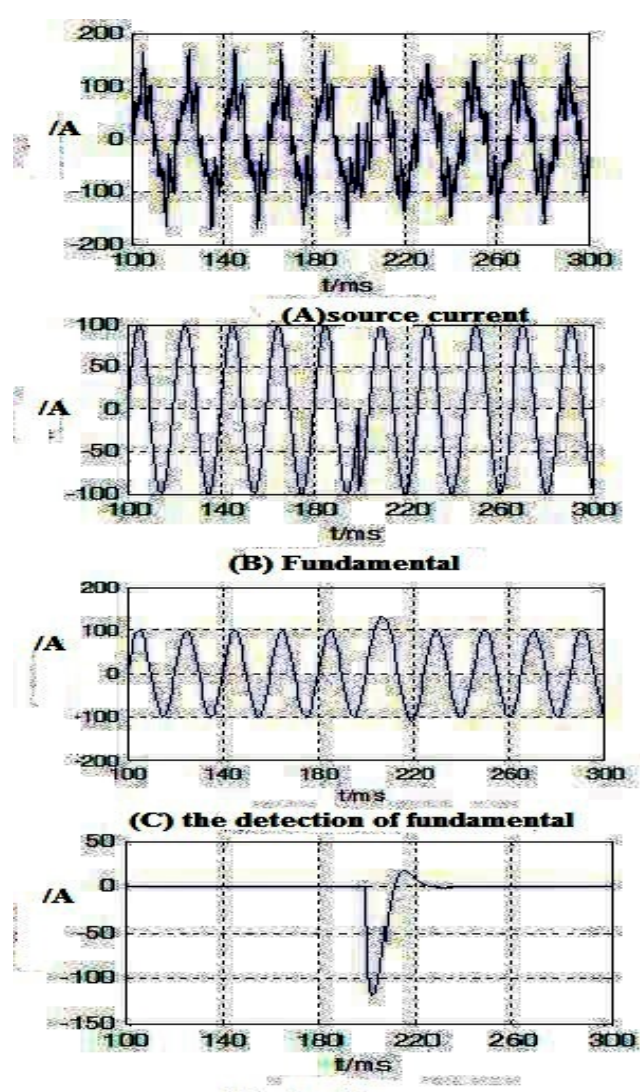

(D) signals error

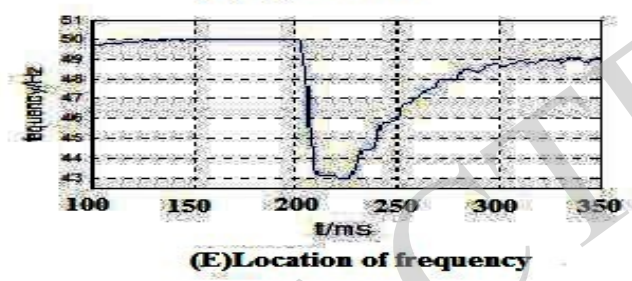

Fig. (8). Simulation results with current frequency changing.

the frequency of load current is from $50 \mathrm{~Hz}$ to $49 \mathrm{~Hz}$. The related parameters of distorted currents are shown in Table 3. The location and detection of Power quality disturbances are shown in Fig. (8) and Fig. (9).

As can be seen from the Fig. (8) and Fig. (9), the proposed method can identified the frequency change within one power cycle $(20 \mathrm{~ms})$ and location of the frequency and the amplitude of different frequency harmonics. The proposed method has a good anti-interference ability to $20 \mathrm{~dB}$ whitenoise.

\section{CONCLUSION}

In this paper, the power quality disturbance location based on BP-RLS is studied. Moreover two different complex disturbance signals are detected by NLS and BP-RLS. With the help of Matlab 7, the simulation results show that the proposed method can improve the convergence rate, and the harmonics parameters, including amplitudes, phase angles and disturbance time, can be detected precisely.
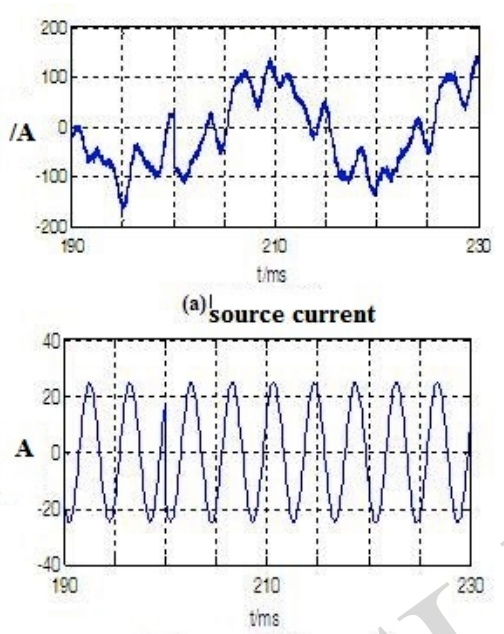

(b) 5 th harmonics

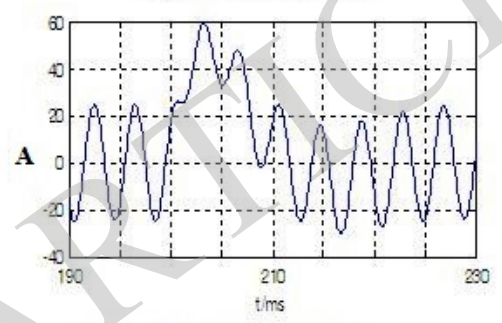

(c) the detection of 5th harmonics

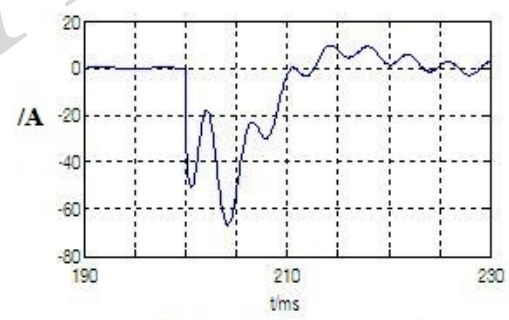

(d) the signal error

Fig. (9). 5th harmonic current detection.

\section{CONFLICT OF INTEREST}

The authors confirm that this article content has no conflict of interest.

\section{ACKNOWLEDGEMENTS}

The Project Supported by Fujian Provincial Major Scientific and Technological Projects under grant 2014H6028, Scientific Research Items of XMUT under grant XYK201401, XMUT Initializing Foundation under grant YKJ12010R, and funding (type A) (funding number: JA12253) from the Fujian Education Department. Xiamen Science \&Technology Plan Project (3502Z20123043).

\section{REFERENCES}

[1] S. Shukla, S. Mishra, and B. Singh, "Empirical-mode decomposition with hilbert transform for power-quality assessment", IEEE Transactions on Power Delivery, vol. 24, no. 4, pp. 2159-2165, 2009. 
[2] E. C. Bentley, G. A. Putrus, S. McDonald, and P. Minns, "Power quality disturbance source identification using self-organising maps", Generation, IET Transmission \& Distribution, vol. 10, no. 4, pp. 1188-1196, 2010.

[3] P. K. Ray, N. Kishor, and S. R. Mohanty, "Islanding and power quality disturbance detection in grid-connected hybrid power system using wavelet and s-transform", IEEE Transactions on Smart Grid, vol. 3, no. 3, pp. 1082- 1094, 2012.

[4] W. G. Morsi, C. P. Diduch, C. Liuchen, and M. E. El-Hawary, "Wavelet-based reactive power and energy measurement in the presence of power quality disturbances", IEEE Transactions on Power Systems, vol. 26, no. 3, pp. 1263- 1271, 2011.

[5] M. Valtierra-Rodriguez, R. de Jesus Romero-Troncoso, R. A. Osornio-Rios, and A. Garcia-Perez, "Detection and classification of single and combined power quality disturbances using neural networks", IEEE Transactions on Industrial Electronics, vol. 61, no. 5, pp. 2473- 2482, 2014,.

[6] B. V. Krishna, and K. Baskaran, "Parallel computing for efficient time-frequency feature extraction of power quality disturbances", IET Signal Processing, vol. 7, no. 4, pp. 312- 326, 2013.

[7] M. S. Manikandan, S. R. Samantaray, and I. Kamwa, "Detection and classification of power quality disturbances using sparse signal decomposition on hybrid dictionaries", IEEE Transactions on Instrumentation and Measurement, vol. 64, no. 1, pp. 27-38, 2015.

[8] C. - Y. Lee, and S. Yi-Xing, "Optimal feature selection for powerquality disturbances classification", IEEE Transactions on Power Deliver, vol. 26, no. 4, pp. 2342-2351, 2011.

[9] P. K. Ray, S. R. Mohanty, N. Kishor, and J. P. S. Catalao, "Optimal feature and decision tree-based classification of power quality disturbances in distributed generation systems", IEEE Transactions on Sustainable Energy, vol. 5, no. 1, pp. 200-208, 2014.

[10] P. K. Ray, S. R. Mohanty, and N. Kishor, "Classification of power quality disturbances due to environmental characteristics in distributed generation system", IEEE Transactions on Sustainable Energy, vol. 4, no. 2, pp. $302-313,2013$.

[11] S. -H. Cho, J. Gilsoo, and K. Sae-Hyuk, "Time-frequency analysis of power-quality disturbances via the gabor-wigner transform", IEEE Transactions on Power Delivery, vol. 25, no. 1, pp. 494-499, 2010.
[12] H. Eristi, and Y. Demir, "Automatic classification of power quality events and disturbances using wavelet transform and support vector machines", IET Generation, Transmission \& Distribution, vol. 6, no. 10, pp. 968-976, 2012.

[13] F. B. Costa, "Boundary wavelet coefficients for real-time detection of transients induced by faults and power-quality disturbances", IEEE Transactions on Power Delivery, vol. 29, no. 6, pp. 26742687, 2014.

[14] K. V. Bhadane, M. S. Ballal, and R. M. Moharil, "Wavelet transform based power quality analysis of grid connected wind farm - an investigation of power quality disturbances," In: International Conference on Advances in Electrical Engineering (ICAEE), 2014, pp. $1-6$.

[15] C. -I. Chen, "Virtual multifunction power quality analyzer based on adaptive linear neural network", vol. 59, no. 8, pp. 3321-3329, 2012.

[16] A. D. Paquette, and D. M. Divan, "Providing improved power quality in microgrids: difficulties in competing with existing power-quality solutions", IEEE Industry Applications Magazine, vol. 20, no. 5, pp. 34-43, 2014.

[17] P. Wall, and V. Terzija, "Simultaneous estimation of the time of disturbance and inertia in power systems", IEEE Transactions on Power Delivery, vol. 29, no. 4, pp. 2018- 2031, 2014.

[18] M. Biswal, and P. K. Dash, "Measurement and classification of simultaneous power signal patterns with an s-transform variant and fuzzy decision tree", IEEE Transactions on Industrial Informatics, vol. 9, no. 4, pp. 1819- 1827, 2013.

[19] N. C. F. Tse, J. Y. C. Chan, L. Wing-Hong, L. L. Loi, "Hybrid wavelet and hilbert transform with frequency-shifting decomposition for power quality analysis", IEEE Transactions on Instrumentation and Measurement, vol. 61, no. 12, pp. 3225- 3233, 2012.

[20] Y. Ren-Feng, A. Qian, and H. Xing, "Research on dynamic load modelling based on power quality monitoring system", IET Transmission \& Distribution Generation, vol. 7, no. 1, pp. 46- 51, 2012.

[21] Z. Fengzhan, and Y. Rengang, "Voltage sag disturbance detection based on short time Fourier transforms," In: Proceedings of the CSEE, 2007, vol. 27, no. 10, pp. 28-34, 109.

\begin{tabular}{|c|c|c|}
\hline Received: October 16, 2014 & Revised: December 23, 2014 & Accepted: December 31, 2014 \\
\hline
\end{tabular}

This is an open access article licensed under the terms of the Creative Commons Attribution Non-Commercial License (http://creativecommons.org/licenses/by$\mathrm{nc} / 3.0 /$ ) which permits unrestricted, non-commercial use, distribution and reproduction in any medium, provided the work is properly cited. 